\title{
Effects of water on pyridine pyrolysis: A reactive force field molecular dynamics study
}

\author{
Zhongze Bai $^{\text {a }}$, Xi Zhuo Jiang ${ }^{\text {b, ** }}$, Kai H. Luo ${ }^{\text {a, * }}$ \\ ${ }^{a}$ Department of Mechanical Engineering, University College London, Torrington Place, London, WC1E 7JE, UK \\ b School of Mechanical Engineering and Automation, Northeastern University, Shenyang, Liaoning, 110819, PR China
}

\section{A R T I C L E I N F O}

\section{Article history:}

Received 26 April 2021

Received in revised form

18 July 2021

Accepted 12 August 2021

Available online 16 August 2021

\section{Keywords:}

Pyridine pyrolysis

Water

Reactive force field molecular dynamics

Reaction pathway

\begin{abstract}
A B S T R A C T
The emission of nitrogen oxides (NOx) from coal combustion causes serious environmental problems. Fuel splitting and staging is a promising method for NOx control by combustion modification. In this process, nitrogen-containing compounds generated from pyrolysis gas play an important role in regulating NOx generation. Water from coal could potentially change reactions during the coal pyrolysis process. Adjusting the content of water in coal may be an effective way to control coal pyrolysis reactions. This work aims to investigate the effects of water on pyridine (a main nitrogen-containing compound in coal) pyrolysis via reactive force field (ReaxFF) molecular dynamics (MD) simulations. Results indicate that the addition of water during the pyridine pyrolysis process increases the number of $\mathrm{OH}$ radicals in the system and accelerates the consumption of pyridine at the initial stage. However, at a later stage, water inhibits the consumption of pyridine as it impedes the condensation reaction of pyridine molecules. Common and unique intermediates are identified and quantified under various water-content conditions. Results suggest that water also reduces the proportion of nitrogen atoms in the polycondensation product. Furthermore, ring opening processes of pyridine molecules are reproduced at the atomic level. The changes in reaction pathways due to the presence of water are also revealed. The new insights into the mechanisms of pyridine pyrolysis under water and water-free conditions provide a possibility to control nitrogen migration during the pyrolysis process, which is of great significance to emission reduction from coal combustion.
\end{abstract}

(C) 2021 The Author(s). Published by Elsevier Ltd. This is an open access article under the CC BY license (http://creativecommons.org/licenses/by/4.0/).

\section{Credit author statement}

ZB performed the research, analysed data and wrote the manuscript draft. XZJ co-supervised the research and revised the manuscript. KHL supervised the project and finalised the manuscript.

\section{Introduction}

The emission of nitrogen oxides (NOx) from coal combustion causes serious environmental problems, such as photochemical smog and acid rain [1]. In recent years, a variety of technologies have been developed for coal combustion to control NOx emissions.

\footnotetext{
* Corresponding author.

** Corresponding author.

E-mail addresses: jiangxz@mail.neu.edu.cn (X.Z. Jiang), k.luo@ucl.ac.uk (K.H. Luo),
}

Fuel staging or reburning is a promising method for NOx control by combustion modification. The idea of fuel reburning is to recycle the NOx formed to nitrogen during combustion. The reburning reactor includes three zones [2]: a main reaction zone, where coal combustion under fuel-lean conditions takes place and NOx is generated, a reburning zone, where reburn fuel is injected and reacts with NOx forming $\mathrm{N}_{2}$, a burnout zone, where air is added to ensure complete combustion of fuel.

Reburning fuels play a key role in NOx reduction during coal combustion. They can be divided into two categories: fossil fuels (such as natural gas, coal and oil) and pyrolysis gas. It is reported that pyrolysis gas has better performance in NOx reduction than fossil fuels [3-5]. In a fuel staging (also termed fuel splitting and staging) process, coal is decomposed to pyrolysis gas and char. Char and pyrolysis gas are primary fuel and reburning fuel respectively. Previous studies [3-5] have identified that the nitrogen-containing compounds in pyrolysis gas is important for effective NOx reduction in the fuel splitting and staging process. Water, an intrinsic component in coal, can accelerate coal pyrolysis process and greatly 
alter products distribution in pyrolysis gas [6]. Therefore, adjusting the content of water in coal could be an effective way to control the $\mathrm{N}$ migration during coal pyrolysis, which has the potential to improve the NOx control performance during coal combustion.

Previous studies have explored chemical effects of water during coal pyrolysis by experiments and simulations. Ouyang and coworkers carried out experiments focusing on the effects of $\mathrm{H}_{2} \mathrm{O}$ during char pyrolysis [7]. They proposed that $\mathrm{H}_{2} \mathrm{O}$ reduced the char generation, stabilized the char structure and increased the char reaction rate. $\mathrm{Hu}$ and co-workers investigated the effects of $\mathrm{H}_{2} \mathrm{O}$ on the pyrolysis of coal [8]. Results showed that the yield of tar and light tar decreased with water content increasing during the coal pyrolysis. Liu and co-workers interrogated pyrrole pyrolysis with water using a density functional theory method [9]. The computational research suggested that $\mathrm{H}_{2} \mathrm{O}$ molecules inhibited the formation $\mathrm{HCN}$ but promoted the generation of $\mathrm{NH}_{3}$. Gou and coworkers explored the effects of water vapor on the pyrolysis products of coal [6]. They found that water promoted the generation of $\mathrm{HCN}, \mathrm{NH}_{3}, \mathrm{H}_{2}$ and $\mathrm{CO}$, which can restrain the NOx formation during coal combustion [6]. Previous studies have made great contributions to understanding the pyrolysis phenomena from a wide range of perspectives, like the composition of products and reaction rate. However, there are some fundamental questions remaining unanswered. For example, the effects of water on the mechanisms of nitrogen-containing compounds pyrolysis in coal are still poorly understood. Further efforts are required to explore the atomic/molecular events therein and reveal the reaction mechanisms.

The current experimental techniques are unable to accurately detect the temporal evolution of the distributions of intermediates and products. Atomistic-scale computational techniques, like reactive molecular dynamics that can capture atomistic behaviors of constitutive atoms/molecules [10], lend the possibility to reveal the detailed reaction mechanisms and obtain intermediate structures [11,12] that cannot be obtained by current measurement methods. Among the existing atomistic methods, the ReaxFF MD is a promising method to simulate complex chemical reactions with reasonable computational cost and high accuracy. Recently, ReaxFF MD simulations have been applied to pyrolysis of coal [13-19] and chemical reactions of nitrogen-containing compounds [20,21]. However, due to the complexity and uncertainty of coal molecular structures, low content of nitrogen, and the influence of other radicals or functional groups [22], it is difficult to build a complete coal molecular model to investigate nitrogen properties during coal pyrolysis. Alternatively, nitrogen-containing compounds in coal such as pyridine $[23,24]$ are used as a surrogate for coal.

In this study, a series of ReaxFF MD simulations are conducted to investigated the effects of water on pyridine pyrolysis. Firstly, effects of water on the pyridine pyrolysis rate and intermediates are studied. Secondly, ring-opening reactions and proportion of polycondensation products are explored during pyrolysis. Finally, reaction mechanisms of principal products like $\mathrm{H}_{2}, \mathrm{CO}, \mathrm{HCN}$ and $\mathrm{NH}_{3}$ are compared between conditions with and without water addition.

\section{Methods}

\subsection{ReaxFF MD}

The ReaxFF is a force field MD method that lies in between quantum chemical simulation and classical molecular dynamics simulation, which was originally developed by van Duin and coworkers [25] to study the kinetics of chemical reactions. ReaxFF employs a bond-order formalism in conjunction with polarizable charge descriptions to determine both reactive and non-reactive interactions between atoms [26]. Energy contributions to the ReaxFF potential are shown in Equation (1):

$\mathrm{E}_{\text {system }}=$

$E_{\text {bond }}+E_{\text {over }}+E_{\text {angle }}+E_{\text {tors }}+E_{\text {vdWaals }}+E_{\text {Coulomb }}+E_{\text {Specific }}$

where the terms are total energy, bond energy, penalty energy, valence angle energy, torsion angle energy, van der Waals energy, Coulomb energy and specific energy, respectively. Further details of ReaxFF are shown in Ref. [26].

\subsection{Case set-ups}

The initial parameters of the simulated systems are shown in Table 1. In each case, the computational domain is a periodic box. System 1 contains 20 pyridine molecules only. In systems 2 to 8 , there are $20-500 \mathrm{H}_{2} \mathrm{O}$ molecules added to investigate the effects of water on pyridine pyrolysis. Fig. 1 shows the model configurations for pyridine pyrolysis without and with water. $\alpha$ is the ratio of the number of water molecules, $n\left(\mathrm{H}_{2} \mathrm{O}\right)$, to the number of pyridine molecules, $\mathrm{n}\left(\mathrm{C}_{5} \mathrm{H}_{5} \mathrm{~N}\right)$, as shown in Equation (2). The density of each system is kept the same at $0.3 \mathrm{~g} / \mathrm{cm}^{3}$ by varying the size of the computational box.

$\alpha=\frac{n\left(\mathrm{H}_{2} \mathrm{O}\right)}{n\left(\mathrm{C}_{5} \mathrm{H}_{5} \mathrm{~N}\right)}$

\subsection{Simulation details}

In this paper, the Large-scale Atomic/Molecular Massively Parallel Simulator (LAMMPS) was used to carry out ReaxFF MD simulations of pyridine pyrolysis. The reactive force field of the $\mathrm{C} / \mathrm{H} / \mathrm{O} / \mathrm{N}$ system was chosen, whose parameters are trained with quantum chemistry calculations and have been carefully validated $[27,28]$. The time step was $0.1 \mathrm{fs}$ and the bond order cutoff value was 0.3 . The NVT ensemble [29] was selected for all simulations. Due to excessive computational cost, MD typically adopts higher temperatures than in the experiments in order to accelerate simulations. This approach has been verified to reproduce reaction mechanisms observed in experiments [30-32].

Before "production" simulations, energy minimization and system equilibration were carried out. The temperature was kept constant at $1000 \mathrm{~K}$ for 50 ps After that, the temperature of each system is increased to a final temperature of $3000 \mathrm{~K}$ with a heating rate of $100 \mathrm{~K} / \mathrm{ps}$ and then kept constant. The total simulation time is $1000 \mathrm{ps}$ Three replicates with different initial positions of reactants were simulated for every case. The simulation was complemented via REAXC package on the platform of Large-scale Atomic/Molecular Massively Parallel Simulator (LAMMPS).

\subsection{Post-processing}

The reaction pathways are obtained by Chemical Trajectory AnalYzer (ChemTraYzer) scripts [33]. The dynamic trajectories were visualised using VMD [34]. Unless otherwise indicated, the data used in the figures of this study are the average results of the three replicate simulations. Error bars in all figures are Standard Error (SE) of three replicates. 
Table 1

Initial parameters of the simulated systems.

\begin{tabular}{|c|c|c|c|c|c|}
\hline System & Number of $\mathrm{C}_{5} \mathrm{H}_{5} \mathrm{~N}$ molecules & Number of $\mathrm{H}_{2} \mathrm{O}$ molecules & $\alpha$ & Density $\left(\mathrm{g} / \mathrm{cm}^{3}\right)$ & $\operatorname{Box} \operatorname{size}(\AA)$ \\
\hline 1 & 20 & 0 & 0 & 0.3 & 20.6118 \\
\hline 2 & 20 & 20 & 1 & 0.3 & 22.0708 \\
\hline 3 & 20 & 40 & 2 & 0.3 & 23.3588 \\
\hline 4 & 20 & 60 & 3 & 0.3 & 24.5186 \\
\hline 5 & 20 & 80 & 4 & 0.3 & 25.5780 \\
\hline 6 & 20 & 100 & 5 & 0.3 & 26.5562 \\
\hline 7 & 20 & 200 & 10 & 0.3 & 30.6168 \\
\hline 8 & 20 & 500 & 25 & 0.3 & 38.8450 \\
\hline
\end{tabular}
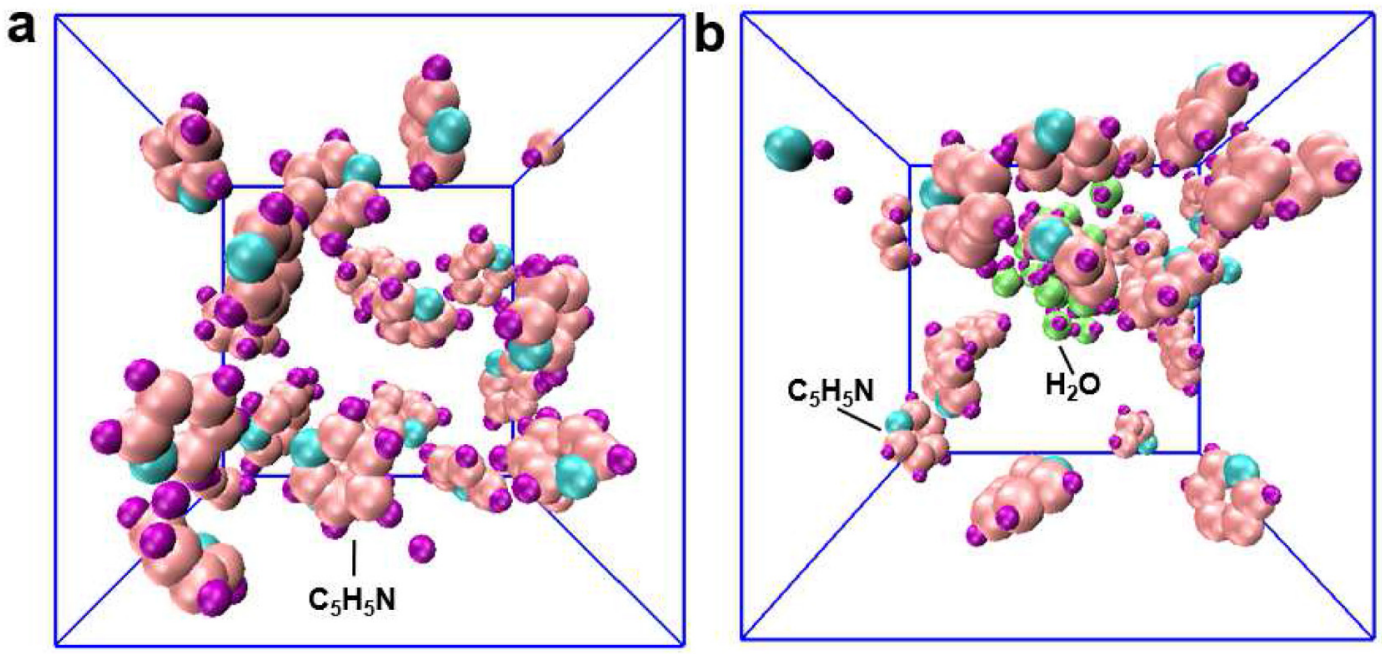

Fig. 1. Initial configurations for pyridine pyrolysis. (a) $\alpha=0$ (b) $\alpha=1$.

\section{Results and discussions}

\subsection{Validation of simulations}

The validation of the ReaxFF MD simulations is achieved by comparing intermediate products obtained from this study with those from previous studies. The key intermediate species are $\mathrm{HCN}$, $\mathrm{CN}, \mathrm{NH}_{3}, \mathrm{H}_{2}$ and $\mathrm{C}_{2} \mathrm{H}_{2}$, which agrees with previous work [30].

The mechanisms of pyridine pyrolysis and chemical effects of water during pyridine pyrolysis are analyzed in the following sections.

\subsection{Effects of water on pyridine consumption rate}

Fig. 2a and $b$ shows the time evolutions of $\mathrm{C}_{5} \mathrm{H}_{5} \mathrm{~N}$ with $\alpha$ value ranging from 0 to 25 at $3000 \mathrm{~K}$. At the initial stage up to $600 \mathrm{ps}$, at least $90 \%$ of $\mathrm{C}_{5} \mathrm{H}_{5} \mathrm{~N}$ molecules are consumed in all cases. To study the water influence on consumption rate of pyridine, the consumption number of pyridine at different stages was calculated as shown in Fig. 2c. It is clear that water promotes pyridine consumption rate during the first 200 ps A similar phenomenon was also observed in previous studies that water can promote reactions during ethanol and methane oxidation and pyrolysis char [7,31,35]. Under water-free conditions, pyridine molecules are consumed by reactions:

$$
\begin{aligned}
& \mathrm{C}_{5} \mathrm{H}_{5} \mathrm{~N}+\mathrm{H} \rightarrow \mathrm{C}_{5} \mathrm{H}_{6} \mathrm{~N} \\
& \mathrm{C}_{5} \mathrm{H}_{5} \mathrm{~N} \rightarrow \mathrm{C}_{5} \mathrm{H}_{4} \mathrm{~N}+\mathrm{H} \\
& \mathrm{C}_{5} \mathrm{H}_{5} \mathrm{~N}+\mathrm{H} \rightarrow \mathrm{C}_{5} \mathrm{H}_{4} \mathrm{~N}+\mathrm{H}_{2}
\end{aligned}
$$

However, $\mathrm{OH}$ radicals are generated with water addition during pyridine pyrolysis by reactions:

$\mathrm{H}_{2} \mathrm{O} \rightarrow \mathrm{OH}+\mathrm{H}$

$\mathrm{H}_{2} \mathrm{O}+\mathrm{H} \rightarrow \mathrm{OH}+\mathrm{H}_{2}$

And new reactions are found during pyridine pyrolysis with water as follows:

$$
\begin{aligned}
& \mathrm{C}_{5} \mathrm{H}_{5} \mathrm{~N}+\mathrm{OH} \rightarrow \mathrm{H}_{2} \mathrm{O}+\mathrm{C}_{5} \mathrm{H}_{4} \mathrm{~N} \\
& \mathrm{C}_{5} \mathrm{H}_{5} \mathrm{~N}+\mathrm{OH} \rightarrow \mathrm{C}_{5} \mathrm{H}_{6} \mathrm{NO}
\end{aligned}
$$

The addition of water during the pyridine pyrolysis process brings $\mathrm{OH}$ radicals in the system and accelerates the consumption of pyridine. More details about the effects of water on intermediates are shown in Table 2, which will be discussed in Section 3.3. However, as the pyrolysis goes on, water presents obvious inhibitory effects on the consumption of pyridine. To explain this phenomenon, we investigated the effects of water on polycondensation compounds in Section 3.4.

\subsection{Effects of water on intermediates}

Fig. 3a and $b$ describe time evolution of the total species number for $\alpha$ ranging from 0 to 25 . In general, the species number during pyrolysis increases to a peak value and then deceases in both cases. And the species number in this case with water is significantly higher than that without water during pyridine pyrolysis. This implies $\mathrm{H}_{2} \mathrm{O}$ molecules take part in various intermediate reactions 

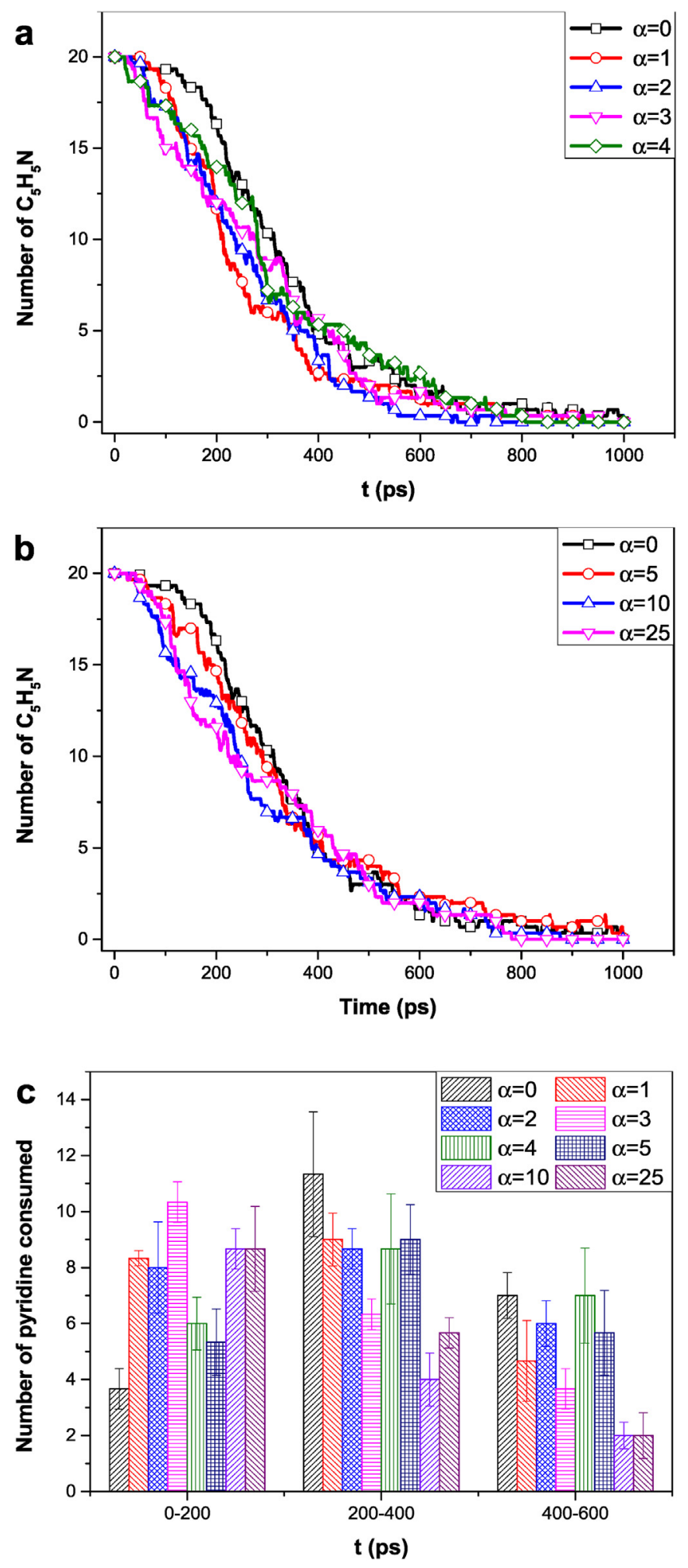

Fig. 2. Time evolution of $\mathrm{C}_{5} \mathrm{H}_{5} \mathrm{~N}$ under varying $\alpha$ values and consumption number of pyridine at different stages. (a) $\alpha=0-4$. (b) $\alpha=0 \& 5-25$. (c) consumption number of pyridine.

and generate additional intermediates during the pyrolysis process. This result is also confirmed by results in Section 3.2 that water molecules produce $\mathrm{OH}$ radicals during pyridine pyrolysis, which promote the consumption of pyridine. Besides, when the value of $\alpha$
Table 2

Main intermediates among cases with and without water addition. Different symbols are used to clarify the influence of water on intermediates. $\bullet: \alpha=0-25$, $\alpha=1-25, \boldsymbol{\uparrow}: \alpha=2-25, \Delta: \alpha=4-25, \square: \alpha=5-25, \times: \alpha=10-25, \otimes: \alpha=3-5 \& 25$, $\oplus: \alpha=4 \& 5 \& 25, \boldsymbol{\vee}: \alpha=5 \& 25$

\begin{tabular}{|c|c|c|c|c|c|c|c|c|}
\hline$\alpha$ & 0 & 1 & 2 & 3 & 4 & 5 & 10 & 25 \\
\hline $\mathrm{H}_{2}$ & $\bullet$ & $\bullet$ & $\bullet$ & $\bullet$ & $\bullet$ & $\bullet$ & $\bullet$ & $\bullet$ \\
\hline $\mathrm{NH}_{3}$ & $\bullet$ & $\bullet$ & $\bullet$ & $\bullet$ & $\bullet$ & $\bullet$ & $\bullet$ & $\bullet$ \\
\hline $\mathrm{CN}$ & $\bullet$ & $\bullet$ & $\bullet$ & $\bullet$ & $\bullet$ & $\bullet$ & $\bullet$ & $\bullet$ \\
\hline $\mathrm{HCN}$ & $\bullet$ & $\bullet$ & $\bullet$ & $\bullet$ & $\bullet$ & $\bullet$ & $\bullet$ & $\bullet$ \\
\hline $\mathrm{C}_{4} \mathrm{H}_{2}$ & $\bullet$ & $\bullet$ & $\bullet$ & $\bullet$ & $\bullet$ & $\bullet$ & $\bullet$ & $\bullet$ \\
\hline $\mathrm{C}_{4} \mathrm{H}_{3}$ & $\bullet$ & $\bullet$ & $\bullet$ & $\bullet$ & $\bullet$ & $\bullet$ & $\bullet$ & $\bullet$ \\
\hline $\mathrm{C}_{4} \mathrm{H}_{4}$ & $\bullet$ & $\bullet$ & $\bullet$ & $\bullet$ & $\bullet$ & $\bullet$ & $\bullet$ & $\bullet$ \\
\hline $\mathrm{CO}$ & & $\diamond$ & $\bullet$ & $\bullet$ & $\bullet$ & $\bullet$ & $\bullet$ & $\bullet$ \\
\hline CHNO & & $\bullet$ & $\diamond$ & $\bullet$ & $\bullet$ & $\diamond$ & $\bullet$ & $\diamond$ \\
\hline $\mathrm{CH}_{2} \mathrm{NO}$ & & $\bullet$ & $\bullet$ & $\diamond$ & $\bullet$ & $\diamond$ & $\bullet$ & $\diamond$ \\
\hline $\mathrm{C}_{2} \mathrm{H}_{2} \mathrm{O}$ & & $\bullet$ & $\bullet$ & $\bullet$ & $\bullet$ & $\bullet$ & $\bullet$ & $\diamond$ \\
\hline $\mathrm{C}_{2} \mathrm{H}_{3} \mathrm{O}$ & & $\bullet$ & $\diamond$ & $\diamond$ & $\bullet$ & $\bullet$ & $\bullet$ & $\diamond$ \\
\hline CNO & & & $\uparrow$ & A & A & $\uparrow$ & $\boldsymbol{p}$ & 中 \\
\hline $\mathrm{CHO}$ & & & \$ & \$ & \$ & $\$$ & \$ & ๑ \\
\hline $\mathrm{CHO}_{2}$ & & & $\uparrow$ & \$ & \$ & $\uparrow$ & \$ & A \\
\hline $\mathrm{C}_{2} \mathrm{HO}_{2}$ & & & $\uparrow$ & \$ & \$ & \$ & \$ & \$ \\
\hline $\mathrm{CO}_{2}$ & & & & & $\Delta$ & $\Delta$ & $\Delta$ & $\Delta$ \\
\hline $\mathrm{C}_{4} \mathrm{H}_{3} \mathrm{O}$ & & & & & & $\square$ & $\square$ & $\square$ \\
\hline $\mathrm{C}_{3} \mathrm{H}_{4} \mathrm{O}$ & & & & & & & $\times$ & $\times$ \\
\hline $\mathrm{C}_{4} \mathrm{H}_{4} \mathrm{O}$ & & & & & & & $\times$ & $\times$ \\
\hline $\mathrm{C}_{2} \mathrm{O}_{2}$ & & & & $\otimes$ & $\otimes$ & $\otimes$ & & $\otimes$ \\
\hline $\mathrm{C}_{3} \mathrm{H}_{2} \mathrm{O}$ & & & & & $\oplus$ & $\oplus$ & & $\oplus$ \\
\hline $\mathrm{C}_{3} \mathrm{H}_{3} \mathrm{O}$ & & & & & & $\bullet$ & & $\bullet$ \\
\hline
\end{tabular}

is higher than 5 , the number of species in the system remains more or less the same even with $\alpha$ increasing.

To further clarify the influence of water molecules on intermediates during pyridine pyrolysis, the intermediates are compared among cases under water-free and water conditions as shown in Table 2. $\mathrm{H}_{2}, \mathrm{NH}_{3}, \mathrm{CN}, \mathrm{HCN}, \mathrm{C}_{4} \mathrm{H}_{2}, \mathrm{C}_{4} \mathrm{H}_{3}$ and $\mathrm{C}_{4} \mathrm{H}_{4}$ are shared among all cases. $\mathrm{CO}, \mathrm{CHNO}, \mathrm{CH}_{2} \mathrm{NO}, \mathrm{C}_{2} \mathrm{H}_{2} \mathrm{O}$ and $\mathrm{C}_{2} \mathrm{H}_{3} \mathrm{O}$ are found in cases with water addition.

$\mathrm{CNO}, \mathrm{CHO}, \mathrm{CHO}_{2}$ and $\mathrm{C}_{2} \mathrm{HO}_{2}$ are observed for $\alpha$ over $2-25 . \mathrm{CO}_{2}$ is produced in $\alpha=4-25$ cases. $\mathrm{C}_{4} \mathrm{H}_{3} \mathrm{O}$ is spotted in cases with $\alpha$ of 5-25. $\mathrm{C}_{3} \mathrm{H}_{4} \mathrm{O}$ and $\mathrm{C}_{4} \mathrm{H}_{4} \mathrm{O}$ are detected when $\alpha$ is 10 or $25 . \mathrm{C}_{2} \mathrm{O}_{2}$ occurs in $\alpha=3,4,5$ and 25 cases. $\mathrm{C}_{3} \mathrm{H}_{2} \mathrm{O}$ and $\mathrm{C}_{3} \mathrm{H}_{3} \mathrm{O}$ are found in $\alpha=4,5,25$ and $\alpha=5,25$ cases, respectively.

\subsection{Effects of water on polycondensation compounds}

During coal pyrolysis, there are both decomposition and polycondensation reactions. The pyrolysis products are char $\left(\mathrm{C}_{40}+\right)$, tar $\left(C_{5}-C_{40}\right)$ and gas $\left(C_{0}-C_{5}\right)$ in descending order according to the number of $C$ atoms [13]. In this part, water influence on decomposition and polycondensation reactions is explored during pyridine pyrolysis.

Fig. $4 \mathrm{a}-\mathrm{c}$ presents the proportion of $\mathrm{C}, \mathrm{N}$ and $\mathrm{H}$ elements in $\mathrm{C}_{5}+$ during pyridine pyrolysis. With the increase of water molecules in system, the percentages of $\mathrm{C}, \mathrm{N}$ and $\mathrm{H}$ in $\mathrm{C}_{5}+$ decrease greatly. When $\alpha$ is 25 , few $\mathrm{C}_{5}+$ compounds are formed during pyridine pyrolysis. This phenomenon is in agreement with previous experimental studies $[7,8]$. Results show that water molecules greatly inhibit polycondensation reactions and modify pathways to char, tar and gas, which is of great significance to control nitrogen migration during coal pyrolysis. In addition, according to the products analysis of pyridine in the water-free condition, the polycondensation reaction mainly occurs after 200 ps. This provides an explanation for the finding in Section 3.2 that water exerts obvious inhibitory effects on the consumption of pyridine after 200 ps. Fig. $4 \mathrm{~d}$ shows snapshots of $C_{5}+$ with the increasing $\alpha$. As the value of $\alpha$ ranges from 0 to 10 , the number of $C$ atoms contained in the polycondensation product is significantly reduced (from $C_{21}$ to 

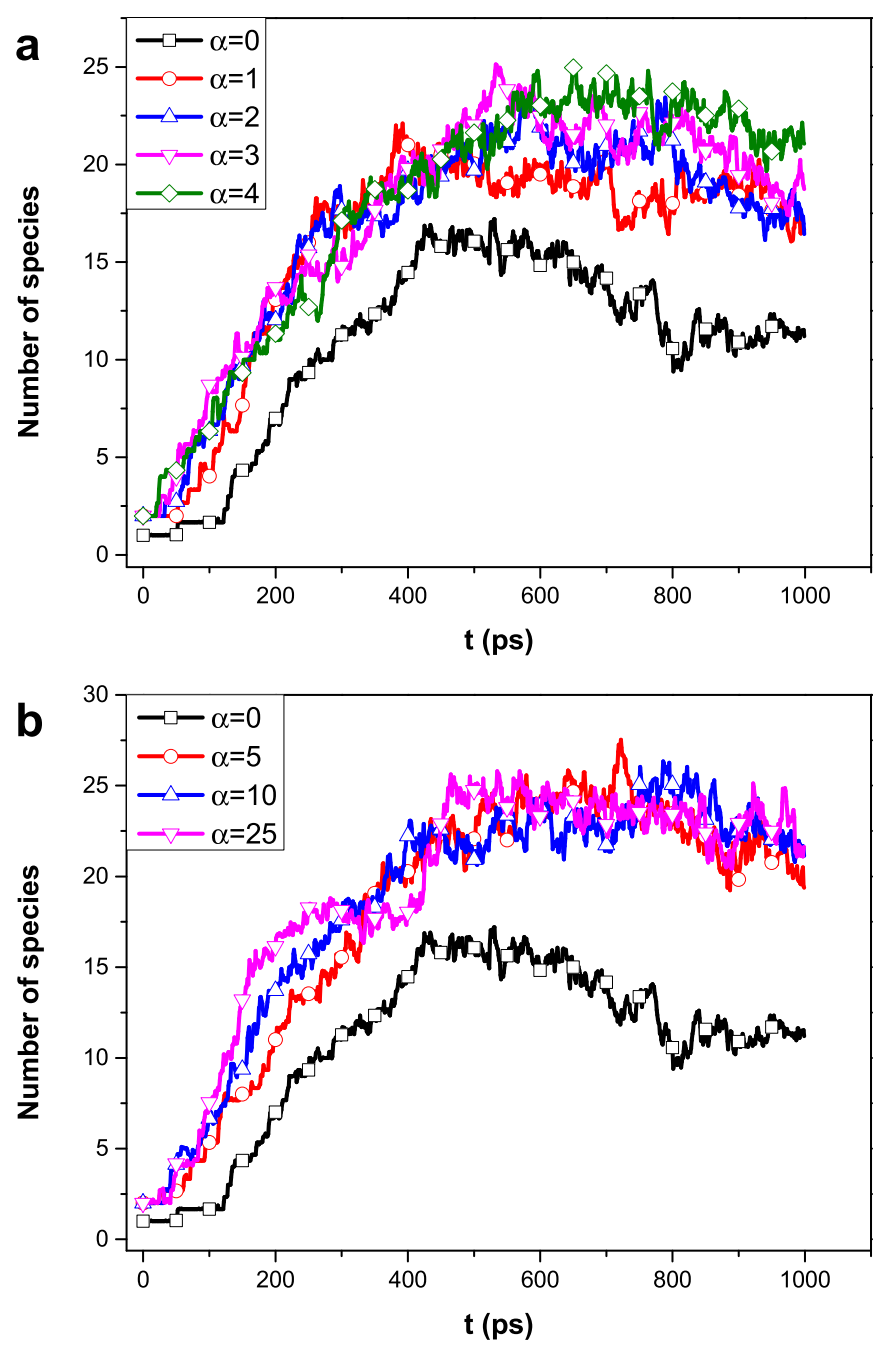

Fig. 3. Time evolution of the total species number under varying $\alpha$ values. (a) $\alpha=0-4$. (b) $\alpha=0 \& 5-25$.

$\mathrm{C}_{6}$ ). Besides, the increase of water molecules also promotes the existence of $\mathrm{O}$ atom in polycondensation products.

\subsection{Effects of water on ring-opening reactions}

According to previous studies [8,9], pyridine molecules undergo ring opening reactions firstly during pyrolysis. Fig. 5a illustrates snapshots of ring-opening reactions during pyridine pyrolysis at all cases. Four types of ring-opening pathways were detected by MD during pyridine pyrolysis. Type $A$ happens when ${ }_{0}-\mathrm{C}_{5} \mathrm{H}_{5} \mathrm{~N}$ reacts with $\mathrm{H}$ atom forming $0-\mathrm{C}_{5} \mathrm{H}_{6} \mathrm{~N}$ firstly. Then $0-\mathrm{C}_{5} \mathrm{H}_{6} \mathrm{~N}$ opens the ring to form a chain $\mathrm{C}_{5} \mathrm{H}_{6} \mathrm{~N}$. Type B occurs when $\mathrm{C}_{5} \mathrm{H}_{5} \mathrm{~N}$ directly opens the ring to generate chain $\mathrm{C}_{5} \mathrm{H}_{5} \mathrm{~N}$. Type $\mathrm{C}$ is the case when pyridine molecules lose an $\mathrm{H}$ atom and then undergoes a ring-opening reaction, which is in agreement with previous studies [31,36-38]. Type D occurs when $\mathrm{C}_{5} \mathrm{H}_{5} \mathrm{~N}$ reacts with $\mathrm{OH}$ radicals in the system to form an oxygen-containing intermediate and then ring-opening reaction occurs. As it happens, the $\mathrm{H}$ atom on the $\mathrm{C}$ atom adjacent to $\mathrm{N}$ atom is transferred to the $\mathrm{N}$ in all types. After that, chain intermediates $\left(C_{5}\right)$ are pyrolyzed and $\mathrm{HCN}, \mathrm{CN}, \mathrm{C}_{4} \mathrm{H}_{4}$ and $\mathrm{C}_{4} \mathrm{H}_{3}$ are generated. The effects of water on key species will be discussed in detail in Section 3.6.

Fig. 5b shows the proportion of each type under different $\alpha$ values. As the content of water molecules in the system increases, the proportion of pyridine molecules to open rings through type $\mathrm{A}$ and type $B$ decreases. Besides, the percentage of type $C$ increases to the peak point at $\alpha=10$ and then decreases with increasing value of $\alpha$. Ring-opening reactions of type $D$ only occurs when the water content in the system is high. In pyridine pyrolysis without water addition, pyridine molecules convert to $\mathrm{C}_{5} \mathrm{H}_{6} \mathrm{~N}$ and $\mathrm{C}_{5} \mathrm{H}_{4} \mathrm{~N}$ through $\mathrm{R} 1$ to $\mathrm{R} 3$. The water addition brings about $\mathrm{OH}$ radical by reactions $\mathrm{R} 4$ and $\mathrm{R} 5$. And the $\mathrm{OH}$ radical promotes the generation of $\mathrm{C}_{5} \mathrm{H}_{4} \mathrm{~N}$ by R6. Thus, water suppresses the ring-opening reactions via type $A$ and type $\mathrm{B}$ and promotes type $\mathrm{C}$ of ring-opening reactions. However, when the value of $\alpha$ increases to 4 , there are pathways to generate oxygen-containing intermediates $\left(\mathrm{C}_{5} \mathrm{H}_{6} \mathrm{NO}, \mathrm{C}_{5} \mathrm{H}_{5} \mathrm{NO}\right.$, $\mathrm{C}_{5} \mathrm{H}_{4} \mathrm{NO}$ and $\mathrm{C}_{5} \mathrm{H}_{3} \mathrm{NO}$ ). Those are:

$$
\begin{aligned}
& \mathrm{C}_{5} \mathrm{H}_{5} \mathrm{~N}+\mathrm{OH} \rightarrow \mathrm{C}_{5} \mathrm{H}_{6} \mathrm{NO}(\mathrm{R} 7) \\
& \mathrm{C}_{5} \mathrm{H}_{4} \mathrm{~N}+\mathrm{H}_{2} \mathrm{O} \rightarrow \mathrm{C}_{5} \mathrm{H}_{6} \mathrm{NO} \\
& \mathrm{C}_{5} \mathrm{H}_{4} \mathrm{~N}+\mathrm{H}_{2} \mathrm{O} \rightarrow \mathrm{C}_{5} \mathrm{H}_{5} \mathrm{NO}+\mathrm{H} \\
& \mathrm{C}_{5} \mathrm{H}_{4} \mathrm{~N}+\mathrm{HO} \rightarrow \mathrm{C}_{5} \mathrm{H}_{5} \mathrm{NO} \\
& \mathrm{C}_{5} \mathrm{H}_{6} \mathrm{NO} \rightarrow \mathrm{C}_{5} \mathrm{H}_{5} \mathrm{NO}+\mathrm{H} \\
& \mathrm{C}_{5} \mathrm{H}_{5} \mathrm{NO}+\mathrm{HO} \rightarrow \mathrm{H}_{2} \mathrm{O}+\mathrm{C}_{5} \mathrm{H}_{4} \mathrm{NO} \\
& \mathrm{C}_{5} \mathrm{H}_{4} \mathrm{NO} \rightarrow \mathrm{C}_{5} \mathrm{H}_{3} \mathrm{NO}+\mathrm{H}
\end{aligned}
$$

Results indicate that $\mathrm{H}_{2} \mathrm{O}$ accelerates the consumption of $\mathrm{C}_{5} \mathrm{H}_{4} \mathrm{~N}$ and promotes the production of oxygen-containing intermediates. That is the reason why high concentration of water has an inhibitory effect on type $C$ and type D only occurs in systems with high water concentration.

\subsection{Effects of water on products $\mathrm{H}_{2}, \mathrm{CO}, \mathrm{HCN}$ and $\mathrm{NH}_{3}$}

Pyridine molecules undergo ring-opening reactions and then pyrolyze to produce the main intermediates $\mathrm{HCN}, \mathrm{CN}, \mathrm{C}_{4} \mathrm{H}_{4}$ and $\mathrm{C}_{4} \mathrm{H}_{3}$, which is in agreement with previous results [31,36-38]. In this part, we explore the effects of water on those radicals as well as principal products $\mathrm{H}_{2}, \mathrm{NH}_{3}$ and $\mathrm{CO}$ during pyridine pyrolysis.

Fig. 6 presents the effects of $\mathrm{H}_{2} \mathrm{O}$ on the generation of $\mathrm{H}_{2}, \mathrm{CO}$, $\mathrm{HCN}$ and $\mathrm{NH}_{3}$. As the number of $\mathrm{H}_{2} \mathrm{O}$ molecules increases, the yield of $\mathrm{H}_{2}, \mathrm{CO}$ and $\mathrm{NH}_{3}$ shows an upward trend, which is in good agreement with a previous study in Ref. [6]. However, water influence on HCN is more complicated. When the value of $\alpha$ is in the range of $0-3$, the yield of $\mathrm{HCN}$ remains the same. As $\alpha$ increases, a parabolic profile is observed which peaks at $\alpha=10$. According to the findings in Section 3.4, water reduces the content of $\mathrm{C}, \mathrm{H}$ and $\mathrm{N}$ in $\mathrm{C}_{5}+$, which accounts for the increasing trend of $\mathrm{H}_{2}, \mathrm{CO}$ and $\mathrm{NH}_{3}$. To understand the trend of $\mathrm{HCN}$, the influence of water on transfer pathways of main intermediates was interrogated as shown in Fig. $7 a$ and $b$.

In pyridine pyrolysis under water-free conditions, $\mathrm{H}_{2}$ mainly comes from $\mathrm{H}$ in the pyrolysis process, that is

$\mathrm{H}+\mathrm{H} \rightarrow \mathrm{H}_{2}$

Water during the pyrolysis process adds a new pathway to $\mathrm{H}_{2}$ by R5. Fig. 6a describes effects of $\mathrm{H}_{2} \mathrm{O}$ on transfer pathways of nitrogen-containing intermediates. As pyrolysis goes on, HCN and $\mathrm{CN}$ will convert to $\mathrm{NH}_{3}$ in all cases [30]. And the transfer pathway is $\mathrm{HCN} \rightarrow \mathrm{CNH} \rightarrow \mathrm{NH} \rightarrow \mathrm{NH}_{2} \rightarrow \mathrm{NH}_{3}$ [39]. However, due to the conversion of $\mathrm{HCN}$ and $\mathrm{CN}$ to $\mathrm{N}_{2}$ occurring at high temperatures [30], $\mathrm{N}_{2}$ is not observed in our simulations. New pathways $\mathrm{HCN} \rightarrow$ 


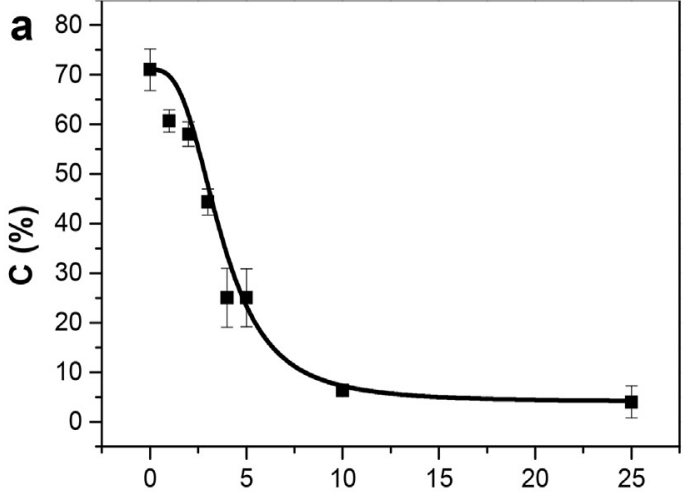

$\alpha$

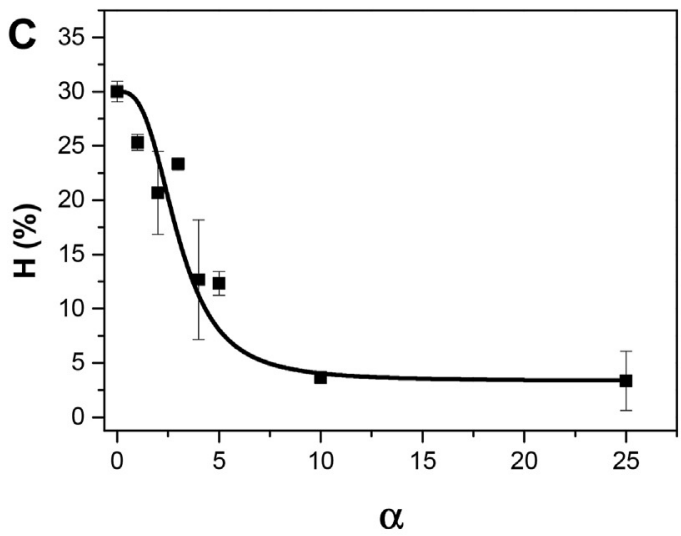

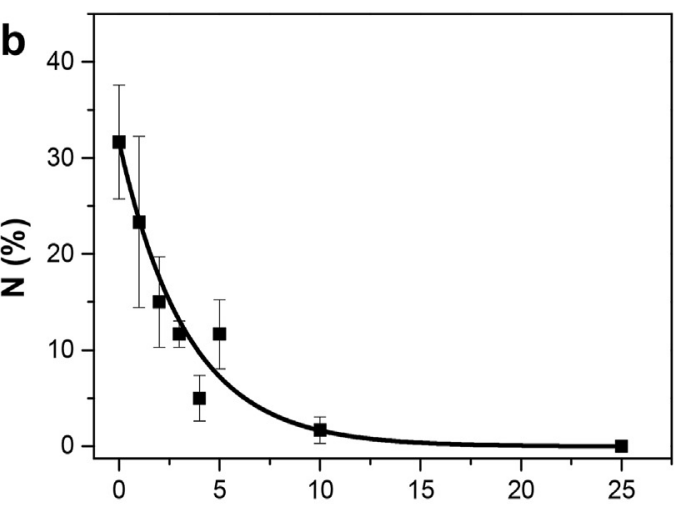

$\alpha$

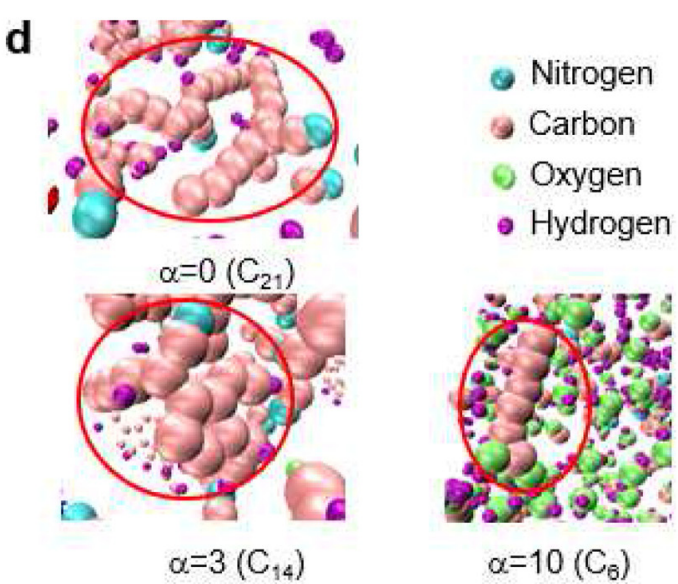

Fig. 4. The proportion of each element in $C_{5}+$ and snapshots of $C_{5}+$ under varying $\alpha$ values. (a) $C$; (b) $N$; (c) $H$; (d) snapshots of $C_{5}+$.

$\mathrm{CH}_{2} \mathrm{NO}$ and $\mathrm{CH}_{2} \mathrm{NO} \rightarrow \mathrm{CHNO}$ are generated with water addition during pyridine pyrolysis by reactions:

$\mathrm{HCN}+\mathrm{OH} \rightarrow \mathrm{CH}_{2} \mathrm{NO}$

$\mathrm{CH}_{2} \mathrm{NO} \rightarrow \mathrm{CHNO}+\mathrm{H}$

When $\alpha$ is greater than 2 , R17 to R20 are found during the pyrolysis process as shown below:

$\mathrm{CN}+\mathrm{OH} \rightarrow \mathrm{CHNO}$

$\mathrm{CN}+\mathrm{H}_{2} \mathrm{O} \rightarrow \mathrm{CHNO}+\mathrm{H}$

$\mathrm{CHNO} \rightarrow \mathrm{CNO}+\mathrm{H}$

$\mathrm{CH}_{2} \mathrm{NO} \rightarrow \mathrm{NH}_{2}+\mathrm{CO}$

Besides, R21 takes place in the range of $\alpha=4-25$ as follows:

$\mathrm{CHNO} \rightarrow \mathrm{CO}+\mathrm{NH}$

Combining the findings from Fig. $6 \mathrm{c}$ and $\mathrm{d}$, it is clear that the influence of $\mathrm{OH}$ radicals on HCN dominates when the value of $\alpha$ is 0 , 1 and 25. Thus, water shows an inhibitory effect on the yield of HCN in those cases. And due to the promotional effects on pyridine pyrolysis, water enhances HCN production over $\alpha=2-10$. Besides, $\mathrm{OH}$ radicals add new pathways of $\mathrm{NH}$ and $\mathrm{NH}_{2}$, which are important precursors to $\mathrm{NH}_{3} . \mathrm{H}_{2} \mathrm{O}$ also enhances the conversion of $\mathrm{NH}_{2}$ to $\mathrm{NH}_{3}$ via reaction:

$\mathrm{H}_{2} \mathrm{O}+\mathrm{NH}_{2} \rightarrow \mathrm{NH}_{3}+\mathrm{HO}$

Therefore, the yield of $\mathrm{NH}_{3}$ is promoted with water addition during pyridine pyrolysis.

Fig. 7b describes water influence on migration pathways of main nitrogen-free intermediates during pyridine pyrolysis. In all cases, $\mathrm{C}_{4} \mathrm{H}_{4}$ and $\mathrm{C}_{4} \mathrm{H}_{3}$ were major initial nitrogen-free species during pyridine pyrolysis [30]. And $\mathrm{C}_{2} \mathrm{H}_{2}$ and $\mathrm{C}_{2} \mathrm{H}$ are mainly produced by thermal decomposition of $\mathrm{C}_{4} \mathrm{H}_{4}$ and $\mathrm{C}_{4} \mathrm{H}_{3} . \mathrm{C}_{4} \mathrm{H}_{2}$ is formed by the loss of one $\mathrm{H}$ atom from $\mathrm{C}_{4} \mathrm{H}_{3}$. In pyridine pyrolysis with water addition, $\mathrm{OH}$ reacts with main intermediates $\left(\mathrm{C}_{4} \mathrm{H}_{3}, \mathrm{C}_{4} \mathrm{H}_{2}, \mathrm{C}_{2} \mathrm{H}_{2}\right.$ and $\mathrm{C}_{2} \mathrm{H}$ ) to form $\mathrm{CO}$. However, there are huge differences in transfer pathways to generating $\mathrm{CO}$ at various $\alpha$ values. When the $\mathrm{H}_{2} \mathrm{O}$ content in the system is low (the value of $\alpha$ in the range 1-4), $\mathrm{OH}$ radicals mainly react with $\mathrm{C}_{2}$ compounds to generate oxygencontaining intermediates by reactions:

$\mathrm{C}_{2} \mathrm{H}+\mathrm{OH} \rightarrow \mathrm{C}_{2} \mathrm{H}_{2} \mathrm{O}$

$\mathrm{C}_{2} \mathrm{H}_{2}+\mathrm{OH} \rightarrow \mathrm{C}_{2} \mathrm{H}_{3} \mathrm{O}$

And $\mathrm{C}_{2} \mathrm{H}_{3} \mathrm{O}, \mathrm{C}_{2} \mathrm{H}_{2} \mathrm{O}$ and $\mathrm{CHO}$ are key precursors forming $\mathrm{CO}$ for $\alpha$ ranging from 1 to 4 . When the range of $\alpha$ is $2-25$, CO will convert to $\mathrm{CHO}_{2}$ through R25:

$\mathrm{CO}+\mathrm{OH} \rightarrow \mathrm{CHO}_{2}$ 

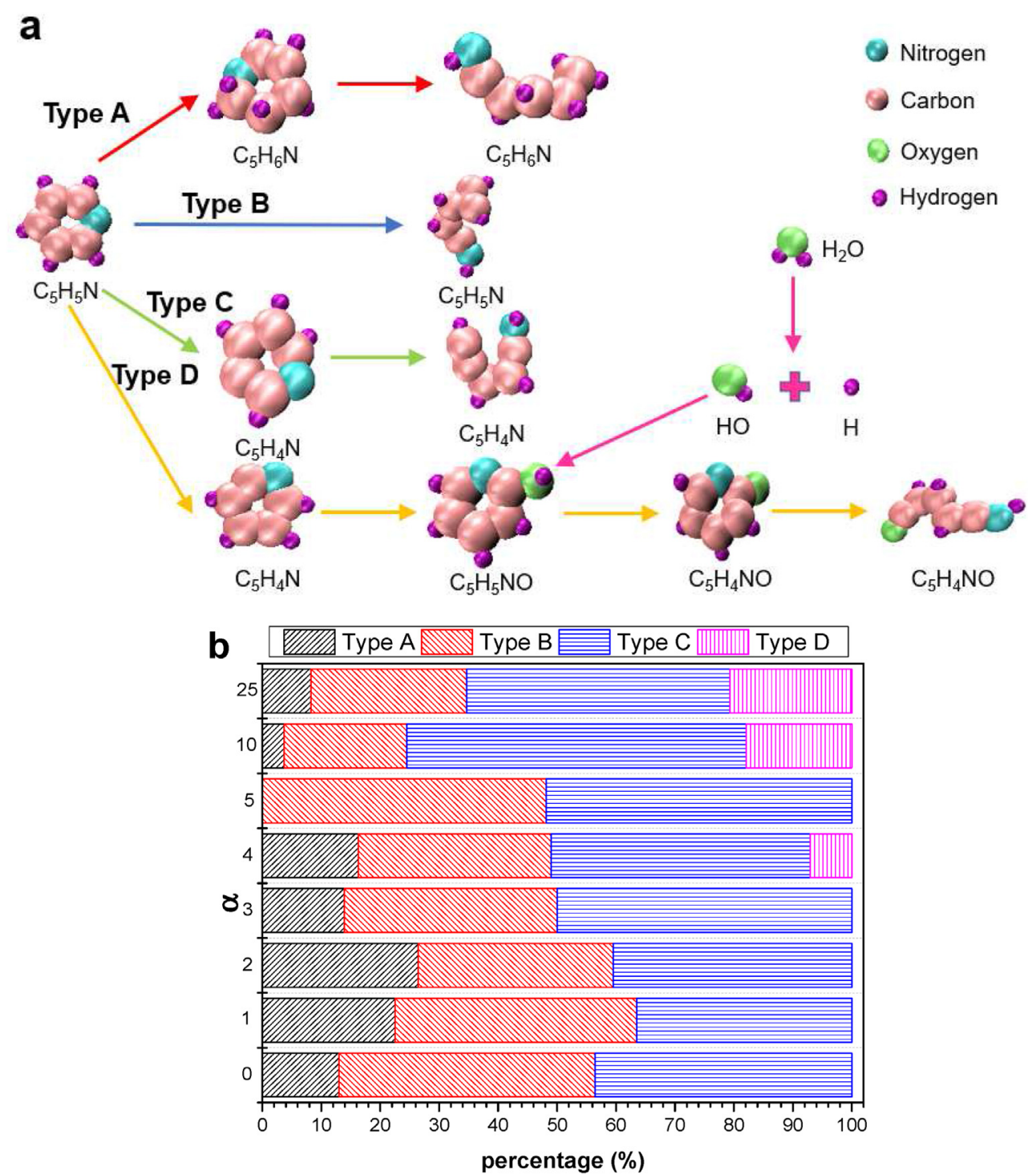

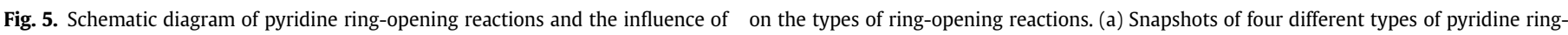
opening. (b) percentages of each type under varying .

And $\mathrm{CO}_{2}$ is generated by decomposition of $\mathrm{CHO}_{2}$ through $\mathrm{R} 26$ with $\alpha=4-25$.

$\mathrm{CHO}_{2} \rightarrow \mathrm{CO}_{2}+\mathrm{H}$

When the value of $\alpha$ is $5-25, \mathrm{OH}$ radicals will react with $\mathrm{C}_{3} \& \mathrm{C}_{4}$ compounds via reactions:

$\mathrm{C}_{3} \mathrm{H}_{3}+\mathrm{OH} \rightarrow \mathrm{C}_{3} \mathrm{H}_{4} \mathrm{O}$

$\mathrm{C}_{4} \mathrm{H}_{2}+\mathrm{OH} \rightarrow \mathrm{C}_{4} \mathrm{H}_{3} \mathrm{O}$

$\mathrm{C}_{4} \mathrm{H}_{3}+\mathrm{OH} \rightarrow \mathrm{C}_{4} \mathrm{H}_{4} \mathrm{O}$

And $\mathrm{C}_{4} \mathrm{H}_{2} \mathrm{O}, \mathrm{C}_{4} \mathrm{H}_{3} \mathrm{O}, \mathrm{C}_{3} \mathrm{H}_{3} \mathrm{O}, \mathrm{C}_{3} \mathrm{H}_{2} \mathrm{O}$ and $\mathrm{C}_{2} \mathrm{O}_{2}$ are key intermediates to form $\mathrm{CO}$. In addition, the pathway $\mathrm{HCN} \rightarrow \mathrm{CH}_{2} \mathrm{NO} \rightarrow \mathrm{CO}$ is broadly shared in water addition cases.

\section{Discussion}

In the present study, ReaxFF MD simulations were conducted to understand the influence of water on nitrogen-containing compounds (pyridine) in coal pyrolysis. We have uncovered new intermediates and reaction pathways that were not reported in previous studies [6,9]. Besides, the effects of water molecules on the consumption rate of pyridine and ring opening processes of pyridine molecules are also revealed at the atomic level. Based on the aforementioned analysis, we have demonstrated that the modification of pyrolysis by water addition can be applied to improve NOx control performance in the fuel splitting and staging process.

In the fuel splitting and staging process, the released nitrogencontaining species from large $\mathrm{N}$-containing compounds are beneficial for NOx reduction as it can reduce nitrogen oxides selectively $[4,5,40]$. However, Greul et al. also proposed that small $\mathrm{N}$ - 

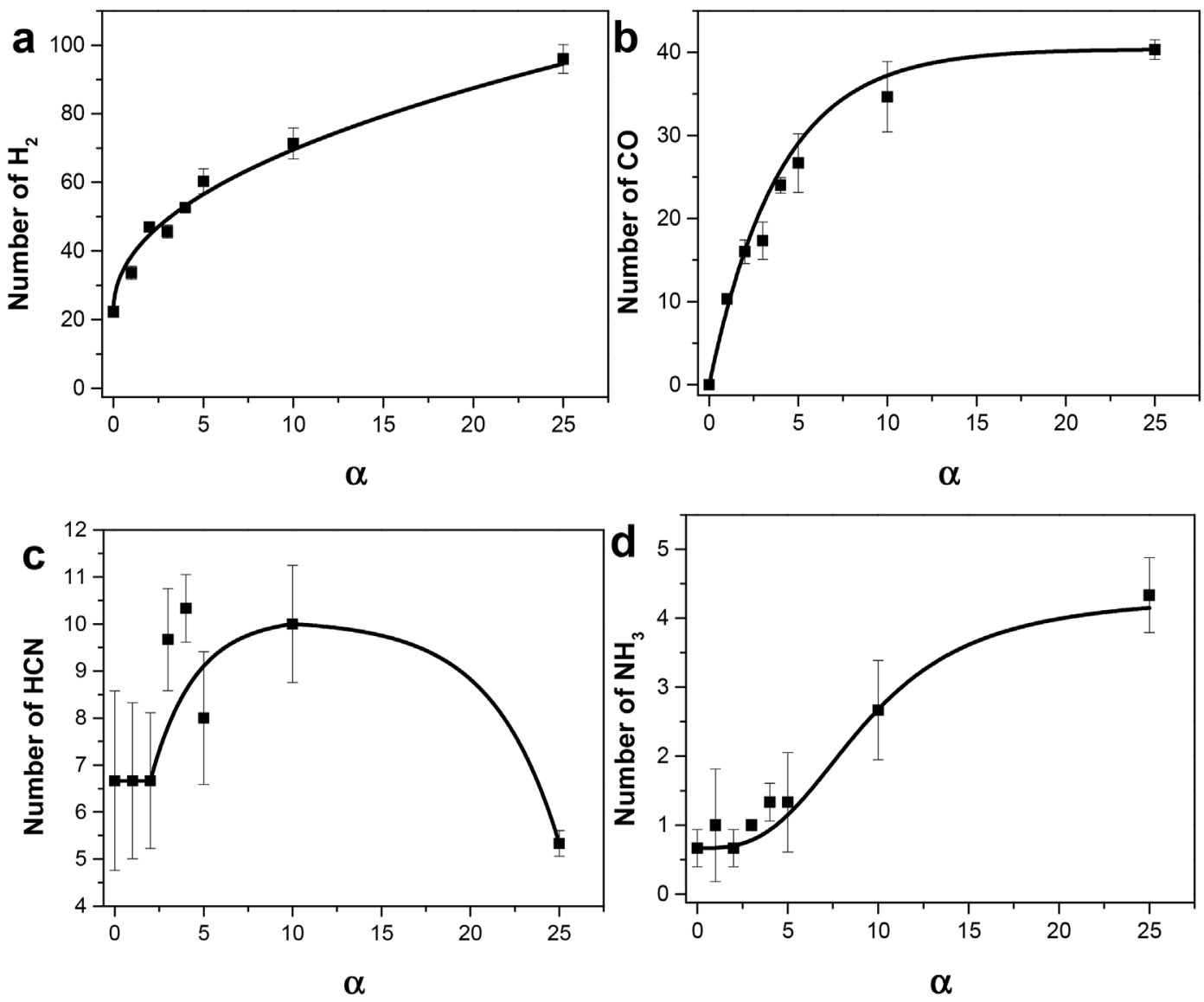

Fig. 6. Effects of $\mathrm{H}_{2} \mathrm{O}$ on the yield of main products. (a) $\mathrm{H}_{2}$. (b) $\mathrm{CO}$. (c) $\mathrm{HCN}$. (d) $\mathrm{NH}_{3}$.

containing species in pyrolysis gas will react with $\mathrm{O}_{2}$ to form NOx, causing negative impact on NOx control [40]. Hence, controlling the proportion of large $\mathrm{N}$-containing compounds in the pyrolysis gas and the pyrolysis process of $\mathrm{N}$-containing compounds is important to reduce NOx emissions. The current results suggest that the addition of water molecules would modify the reaction pathways in the pyrolysis process of $\mathrm{N}$-containing compounds, thus achieving maximum NOx reduction.

Though nitrogen-containing compounds show better NOx reduction performance than nitrogen-free compounds, nitrogenfree radicals can also convert NOx to $\mathrm{N}_{2}$. According to previous studies [41,42], the possibility of non-hydrocarbon fuels, such as $\mathrm{H}_{2}$ and $\mathrm{CO}$, to reduce $\mathrm{NO}$ to $\mathrm{N}_{2}$ is low compared with the hydrocarbon radicals in the reburning process. According to the present research, the addition of water can promote conversion of hydrocarbon compounds to small $C$-containing radicals, which is beneficial for NOx control. On the other hand, high water concentration will convert hydrocarbon compounds into $\mathrm{CO}, \mathrm{CO}_{2}$ and $\mathrm{H}_{2}$, alleviating NOx reduction in the reburning process. Thus, a proper water content in the process of reburning is required if water is used to regulate NO generation.

In general, the regulating effects of water on pyridine pyrolysis is monotonic. This behaviour is beneficial for control of the pyrolysis process. However, there are also non-monotonic behaviors with respect to water content in intermediate species $\left(\mathrm{C}_{2} \mathrm{O}_{2}, \mathrm{C}_{3} \mathrm{H}_{2} \mathrm{O}\right.$ and $\mathrm{C}_{3} \mathrm{H}_{3} \mathrm{O}$ ) and consumption rates of pyridine pyrolysis. For intermediate species $\mathrm{C}_{2} \mathrm{O}_{2}, \mathrm{C}_{3} \mathrm{H}_{2} \mathrm{O}$ and $\mathrm{C}_{3} \mathrm{H}_{3} \mathrm{O}$, when the value of $\alpha$ is lower than 10 , the process is controlled by the condensation reaction of species (CO reacts with $\mathrm{CO}, \mathrm{C}_{2} \mathrm{H}_{2}$ and $\mathrm{C}_{2} \mathrm{H}_{3}$, respectively). It is found that the yields of $\mathrm{C}_{2} \mathrm{O}_{2}, \mathrm{C}_{3} \mathrm{H}_{2} \mathrm{O}$ and $\mathrm{C}_{3} \mathrm{H}_{3} \mathrm{O}$ are low, and their roles in the conversion of NOx to $\mathrm{N}_{2}$ are insignificant [41,42]. Thus, their effects on NOx control can be neglected. The non-monotonic relationship between water content and pyridine consumption rates suggest that different strategies for NOx control are required as the reaction evolves at different stages.

\section{Conclusions}

In this study, pyridine pyrolysis without and with water were investigated via ReaxFF-MD simulations. The effects of the added water with different proportions on pyridine pyrolysis reactions were investigated in detail. It is found that the addition of water during the pyridine pyrolysis process facilitates the generation of $\mathrm{OH}$ radicals and accelerates the consumption of pyridine at the initial stage of pyrolysis. By contracts, as water greatly inhibits the condensation reaction of pyridine molecules, water exerts inhibitory effects on the consumption of pyridine as pyrolysis goes on. Furthermore, water has significant influence on the total number of species during the pyridine pyrolysis and intermediates are identified and quantified under various conditions. In addition, water also reduces the $\mathrm{N}$ content in the polycondensation product $\left(\mathrm{C}_{5}+\right)$. This research provides new insights into atomic-level mechanisms 
a 4-25

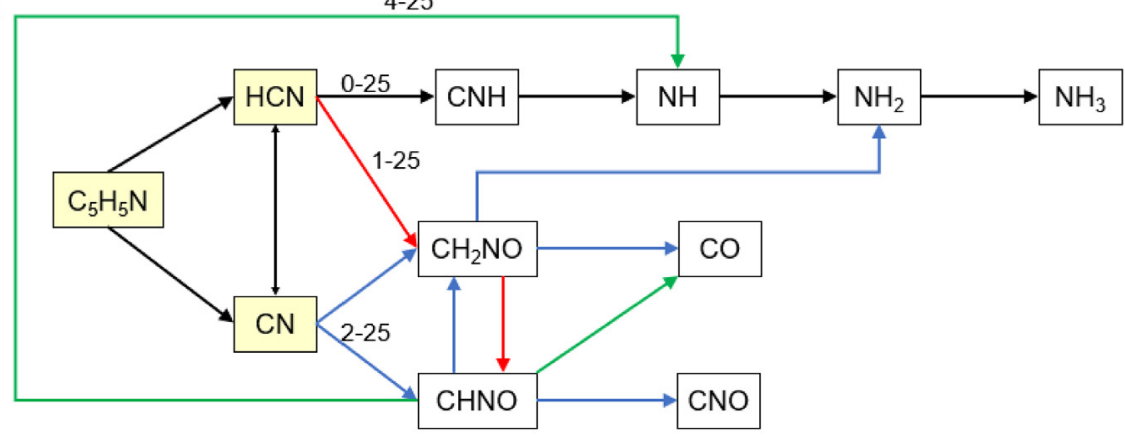

Black: 0-25 Red: 1-25 Blue: 2-25 Green: 4-25

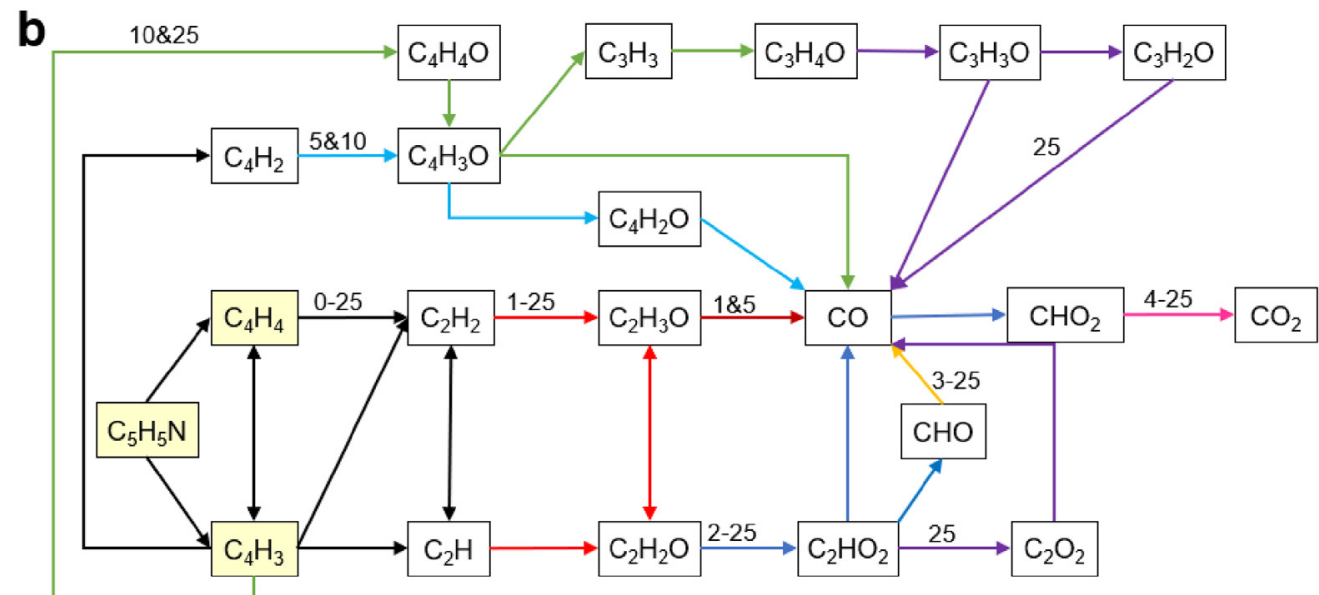

Black: 0-25 Red: 1-25 Dark Red: 1\&5 Blue: 2-25 Yellow: 3-25 Pink: 4-25 Green: 10\&25 Sky Blue: 5\&10 Purple: 25

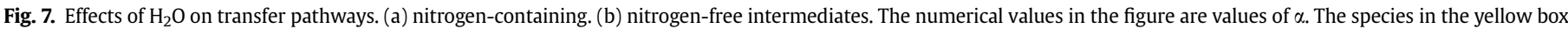
are the starting intermediates. (For interpretation of the references to colour in this figure legend, the reader is referred to the Web version of this article.)

of pyridine pyrolysis under water and water-free conditions, and has implications on control of $\mathrm{N}$ migration during the pyrolysis process and the emission of nitrogenous pollutants from coal pyrolysis and combustion.

\section{Declaration of competing interest}

The authors declare that they have no known competing financial interests or personal relationships that could have appeared to influence the work reported in this paper.

\section{Acknowledgements}

This work was supported by the UK Engineering and Physical Sciences Research Council (EPSRC) under the project "UK Consortium on Mesoscale Engineering Sciences (UKCOMES)" (Grant No. EP/R029598/1).

\section{References}

[1] Bowman CT. Control of combustion-generated nitrogen oxide emissions: technology driven by regulation. Symposium (International) on Combustion 1992;24(1):859-78

[2] Luan T, Wang X, Hao Y, Cheng L. Control of NO emission during coal reburning. Appl Energy 2009;86(9):1783-7.

[3] Greul USH, Magel H-C, Schnell U, Rüdiger H, Hein K. Impact of temperature and fuel-nitrogen content on fuel-staged combustion with coal pyrolysis gas. Symposium (International) on Combustion 1996;26:2231-9.

[4] Rüdiger H, Greul U, Spliethoff $H$, Hein KR. Distribution of fuel nitrogen in pyrolysis products used for reburning. Fuel 1997;76(3):201-5.

[5] Rüdiger H, Kicherer A, Greul U, Spliethoff H, Hein K. Pyrolysis gas from biomass and pulverized biomass as reburn fuels in staged coal combustion. Developments in thermochemical biomass conversion. Springer; 1997. p. $1387-98$

[6] Gou X, Zhou J, Liu J, Cen K. Effects of water vapor on the pyrolysis products of pulverized coal. Procedia Environmental Sciences 2012:12:400-7.

[7] Ouyang J, Hong D, Jiang L, Li Z, Liu H, Luo G, et al. Effect of $\mathrm{CO}_{2}$ and $\mathrm{H}_{2} \mathrm{O}$ on char properties. Part 1: pyrolysis char structure and reactivity. Energy Fuels 2020;34(4):4243-50.

[8] Hu E, Zeng X, Ma D, Wang F, Yi X, Li Y, et al. Effect of the moisture content in coal on the pyrolysis behavior in an indirectly heated fixed-bed reactor with internals. Energy Fuels 2017;31(2):1347-54.

[9] Liu J, Lu Q, Jiang X-y, Hu B, Zhang X-l, Dong C-q, et al. Theoretical investigation of the formation mechanism of $\mathrm{NH}_{3}$ and $\mathrm{HCN}$ during pyrrole pyrolysis: the 
effect of $\mathrm{H}_{2} \mathrm{O}$. Molecules 2018;23(4):711.

[10] Jiang XZ, Luo KH, Ventikos Y. Principal mode of Syndecan-4 mechanotransduction for the endothelial glycocalyx is a scissor-like dimer motion. Acta Physiol 2020;228(3):e13376.

[11] Jiang XZ, Feng M, Zeng W, Luo KH. Study of mechanisms for electric field effects on ethanol oxidation via reactive force field molecular dynamics. Proc Combust Inst 2019;37(4):5525-35.

[12] Jiang XZ, Luo KH. Reactive and electron force field molecular dynamics simulations of electric field assisted ethanol oxidation reactions. Proc Combust Inst 2021;38(4):6605-13.

[13] Zheng M, Li X, Liu J, Guo L. Initial chemical reaction simulation of coal pyrolysis via ReaxFF molecular dynamics. Energy Fuels 2013;27(6):2942-51.

[14] Bhoi S, Banerjee T, Mohanty K. Molecular dynamic simulation of spontaneous combustion and pyrolysis of brown coal using ReaxFF. Fuel 2014;136:326-33.

[15] Castro-Marcano F, Russo Jr MF, van Duin AC, Mathews JP. Pyrolysis of a largescale molecular model for Illinois no. 6 coal using the ReaxFF reactive force field. J Anal Appl Pyrol 2014;109:79-89.

[16] Zheng M, Li X, Liu J, Wang Z, Gong X, Guo L, et al. Pyrolysis of Liulin coal simulated by GPU-based ReaxFF MD with cheminformatics analysis. Energy Fuels 2014;28(1):522-34.

[17] Chen B, Diao Z-J, Zhao Y-L, Ma X-X. A ReaxFF molecular dynamics (MD) simulation for the hydrogenation reaction with coal related model compounds. Fuel 2015;154:114-22.

[18] Li W, Zhu Y-m, Wang G, Wang Y, Liu Y. Molecular model and ReaxFF molecular dynamics simulation of coal vitrinite pyrolysis. J Mol Model 2015;21(8):188.

[19] Chenoweth K, Van Duin AC, Goddard WA. ReaxFF reactive force field for molecular dynamics simulations of hydrocarbon oxidation. J Phys Chem 2008;112(5):1040-53.

[20] Han S-p, van Duin AC, Goddard III WA, Strachan A. Thermal decomposition of condensed-phase nitromethane from molecular dynamics from ReaxFF reactive dynamics. J Phys Chem B 2011;115(20):6534-40.

[21] Strachan A, Kober EM, van Duin AC, Oxgaard J, Goddard III WA. Thermal decomposition of RDX from reactive molecular dynamics. J Chem Phys 2005;122(5):054502.

[22] Wang Ca, Du Y, Jin X, Che D. Pyridine and pyrrole oxidation under oxy-fuel conditions. Energy Sources, Part A Recovery, Util Environ Eff 2016;38(7): 975-81.

[23] Solomon PR, Colket MB. Evolution of fuel nitrogen in coal devolatilization. Fuel 1978;57(12):749-55.

[24] Nelson PF, Kelly MD, Wornat MJ. Conversion of fuel nitrogen in coal volatiles to NOx precursors under rapid heating conditions. Fuel 1991;70(3):403-7.

[25] Van Duin AC, Dasgupta S, Lorant F, Goddard WA. ReaxFF: a reactive force field for hydrocarbons. J Phys Chem 2001:105(41):9396-409.

[26] Senftle TP, Hong S, Islam MM, Kylasa SB, Zheng Y, Shin YK, et al. The ReaxFF reactive force-field: development, applications and future directions. npj Computational Materials 2016;2(1):1-14.
[27] Zhang L, Duin ACv, Zybin SV, Goddard Iii WA. Thermal decomposition of hydrazines from reactive dynamics using the ReaxFF reactive force field J Phys Chem B 2009;113(31):10770-8.

[28] Zhang L, Zybin SV, Van Duin AC, Dasgupta S, Goddard III WA, Kober EM. Carbon cluster formation during thermal decomposition of octahydro-1, 3, 5 , 7-tetranitro-1, 3, 5, 7-tetrazocine and 1, 3, 5-triamino-2, 4, 6-trinitrobenzene high explosives from ReaxFF reactive molecular dynamics simulations. J Phys Chem 2009;113(40):10619-40.

[29] Andersen HC. Molecular dynamics simulations at constant pressure and/or temperature. J Chem Phys 1980;72(4):2384-93.

[30] Liu J, Guo X. ReaxFF molecular dynamics simulation of pyrolysis and combustion of pyridine. Fuel Process Technol 2017;161:107-15.

[31] Feng M, Jiang XZ, Zeng W, Luo KH, Hellier P. Ethanol oxidation with high water content: a reactive molecular dynamics simulation study. Fuel 2019;235:515-21.

[32] Hong D, Li P, Si T, Guo X. ReaxFF simulations of the synergistic effect mechanisms during co-pyrolysis of coal and polyethylene/polystyrene. Energy 2021;218:119553.

[33] Döntgen M, Przybylski-Freund M-D, Kröger LC, Kopp WA, Ismail AE, Leonhard K. Automated discovery of reaction pathways, rate constants, and transition states using reactive molecular dynamics simulations. J Chem Theor Comput 2015;11(6):2517-24.

[34] Humphrey W, Dalke A, Schulten K. VMD: visual molecular dynamics. J Mol Graph 1996;14(1):33-8.

[35] Hong D, Liu L, Huang Y, Zheng C, Guo X. Chemical effect of $\mathrm{H}_{2} \mathrm{O}$ on $\mathrm{CH}_{4}$ oxidation during combustion in $\mathrm{O}_{2} / \mathrm{H}_{2} \mathrm{O}$ environments. Energy Fuels 2016;30(10):8491-8.

[36] Mackie JC, Colket MB, Nelson PF. Shock tube pyrolysis of pyridine. J Phys Chem 1990;94(10):4099-106.

[37] Hore N, Russell D. Radical pathways in the thermal decomposition of pyridine and diazines: a laser pyrolysis and semi-empirical study. Journal of the Chemical Society, Perkin Transactions 1998;2(2):269-76.

[38] Memon H, Bartle K, Taylor J, Williams A. The shock tube pyrolysis of pyridine. Int J Energy Res 2000;24(13):1141-59.

[39] Luo J, Zou C, He Y, Jing H, Cheng S. The characteristics and mechanism of NO formation during pyridine oxidation in $\mathrm{O}_{2} / \mathrm{N}_{2}$ and $\mathrm{O}_{2} / \mathrm{CO}_{2}$ atmospheres. Energy 2019;187:115954.

[40] Impact of temperature and fuel-nitrogen content on fuel-staged combustion with coal pyrolysis gas. In: Greul U, Spliethoff H, Magel H-C, Schnell U, Rüdiger H, Hein K, et al., editors. Symposium (international) on combustion. Elsevier; 1996.

[41] Dagaut P, Lecomte F. Experiments and kinetic modeling study of NOreburning by gases from biomass pyrolysis in a JSR. Energy Fuels 2003;17(3):608-13.

[42] Glarborg P, Kristensen PG, Dam-Johansen K, Alzueta M, Millera A, Bilbao R Nitric oxide reduction by non-hydrocarbon fuels. Implications for reburning with gasification gases. Energy Fuels 2000;14(4):828-38. 